\title{
Co morbidity of alcoholism in patients with anxiety and mood disorders
}

\author{
Georgios Moussas*1, Maria Diallina³, Athanasios Tselebis², Kalliopi Vassila- \\ Demi $^{2}$, Dionisios Bratis ${ }^{2}$ and Athanasios Karkanias ${ }^{2}$
}

\begin{abstract}
Address: 1Second Psychiatric Department, "Attikon" General Hospital, University of Athens, Greece, 2Psychiatric Department, "Sotiria" General Hospital, Athens, Greece and "Psychiatric Department, "G. Gennimatas" General Hospital, Athens, Greece

* Corresponding author
\end{abstract}

\author{
from International Society on Brain and Behaviour: 3rd International Congress on Brain and Behaviour \\ Thessaloniki, Greece. 28 November - 2 December 2007 \\ Published: 17 April 2008 \\ Annals of General Psychiatry 2008, 7(Suppl I):S193 doi:I0.II86/I744-859X-7-SI-SI 93
}

This abstract is available from: http://www.annals-general-psychiatry.com/content/7/SI/SI93

(c) 2008 Moussas et al.; licensee BioMed Central Ltd.

\section{Background}

According to the World Health Organization (W.H.O), the alcohol dependence - abuse related disorders presents a prevalence of $1-5 \%$. Furthermore, it is well known that there is a high co-morbidity between mental disorders and alcoholism.

The goal of this study is to investigate and to make a comparison of alcohol use and abuse in patients with anxiety and mood disorders.

\section{Materials and methods}

For a two months period, all the patients examined and diagnosed with anxiety and/or mood disorders (according to D.S.M - IV - TR) in the Emergency Department of two General Hospitals, completed the Cage Test, which traces covered alcoholism problems. The test includes 4 items and is specified to detect alcoholism in the general population and in general hospital patients. Two or more positive answers suggests alcohol dependance - abuse. Residents acquainted with its use gave the test. Finally, we recorded the demographics (sex, age, education and family status) of all examined patients included in the study.

Sample: 130 patients (68 with anxiety disorders and 62 with mood disorders) are included in the study. $49.2 \%$ were males and $50.8 \%$ were females. The mean age of the sample was $42.58( \pm 14.63)$ years and the mean duration of education was $10.98( \pm 4.18)$ years. As to family status,
$41.5 \%$ were married, $39.2 \%$ were single and the rest of them were divorced.

\section{Results}

The mean score of the sample in the Cage Test was $0.73( \pm$ $1.23)$. The corresponding mean score in patients with anxiety disorders was $0.60( \pm 1.04)$ and in patients with mood disordres was $0.87( \pm 1.41)$, with no statistical difference between the two scores ( $t$ test $p>0.05$ ). A percentage of $21.5 \%$ of all patients presented positive score in the test (positive answers $>2$ ). Separating the sample as to diagnosis, $19.1 \%$ of patients with anxiety disorders and $24.2 \%$ of patients with mood disorders presented positive score, with no statistical difference between the two groups ( $\mathrm{x} 2 \mathrm{p}>0.05)$. Male patients had higher mean score in Cage Test than females $(0.95 \pm 1.34$ vs $0.52 \pm 1.08$, t test $\mathrm{p}<0.05)$. There was no correlation between Cage test score and age (Pearson correlation $\mathrm{p}>0.05$ ). As to family status, married patients (mean cage score $0.43 \pm 0.84$ ) presented statistically lower scores in comparison with singles (mean cage score $0.84 \pm 1.30$ ) and divorced patients (mean cage score $1.26 \pm 1.66$ ). We observed negative correlation between the duration of education and cage score in patients with mood disorders (Pearson correlation $\mathrm{p}<$ $0.05, \mathrm{r}=-0.303$ ), in contradiction to patients with anxiety disorders who presented positive correlation (Pearson correlation $\mathrm{p}<0.05, \mathrm{r}=0.259)$. The introduction of age factor doesn't differentiate the correlation above (partial correlation). 


\section{Conclusions}

Our results confirms an increased alcohol abuse in patients with anxiety and mood disorders in comparison with the general population. These patients, probably, use alcohol in order to self - medicate their symptomatology. Demographic factors, like age or family status have a different impact. Although aging seems to reduce alcohol use in the genaral population, this is not observed in our patients. In contrast, family status has a significant role in the pattern of alcohol use. Further studies are required in order to investigate the participant role of the duration of education in the alcohol use and abuse in patients with anxiety and mood disorders.

Publish with Bio Med Central and every scientist can read your work free of charge

"BioMed Central will be the most significant development for disseminating the results of biomedical research in our lifetime. " Sir Paul Nurse, Cancer Research UK

Your research papers will be:

- available free of charge to the entire biomedical community

- peer reviewed and published immediately upon acceptance

- cited in PubMed and archived on PubMed Central

- yours - you keep the copyright

Submit your manuscript here:

http://www.biomedcentral.com/info/publishing_adv.asp 